\title{
National and Local Strategies in the Netherlands for Obesity Prevention and Management in Children and Adolescents
}

\author{
Jacob C. Seidell ${ }^{a, b}$ Jutka Halberstadt ${ }^{a}$ b \\ aDepartment of Health Sciences, Vrije Universiteit, Amsterdam, The Netherlands; \\ ${ }^{b}$ Amsterdam Public Health Research Institute, Amsterdam, The Netherlands
}

\section{Keywords}

Obesity · Overweight · Children · Adolescents · Prevalence - Determinants · Prevention .

Management $\cdot$ Treatment $\cdot$ National strategy $\cdot$ Local strategy $\cdot$ Integrated-systems approach

\begin{abstract}
Background: As in many other countries around the world, the Netherlands has a high prevalence of overweight and obesity in children. About 1 in 7 of children aged 2-19 years has either overweight or obesity. Summary: In this paper the national and local activities aimed at the prevention and management of obesity in children and adolescents in the Netherlands are reviewed. It is recommended to, nationally as well as locally, take an integrated-systems approach that tackles the obesogenic food environment as well as upstream and downstream determinants of obesity. Efforts should take a life course approach and be focused on promoting obesity prevention as well as improving the management of children who already have obesity. The national policies in the Netherlands rely heavily on self-regulation by stakeholders such as supermarkets, restaurants, and the food industry. Local policies and actions such as the whole-systems approach in Amsterdam are promising. Future directions include development of tools for the operationalization and evaluation of local systems approaches. Regulation by national and local governments is necessary to ensure a healthy food environment for children and their families, but health policies require intersectoral action. Key Messages: In the Netherlands many policies are in place or under development, especially at the municipal level (e.g., in Amsterdam), but more substantial action is urgently required.
\end{abstract}


Table 1. Prevalence of overweight and obesity in the Dutch national growth studies using the international body mass index cutoff points $[1,2]$

Table 2. Prevalence of overweight and obesity in the Netherlands by age and ethnicity in 2018 (based on self-reported height and weight) [4]
Seidell and Halberstadt: Childhood Obesity Prevention and Management in the Netherlands

\begin{tabular}{lcrr}
\hline & 1980 & 1997 & 2009 \\
\hline Boys overweight (incl. obesity) & 5.1 & 9.4 & 13.3 \\
Boys obesity & 0.3 & 0.9 & 1.8 \\
Girls overweight (incl. obesity) & 7.2 & 11.9 & 14.9 \\
Girls obesity & 0.5 & 1.6 & 2.2 \\
\hline
\end{tabular}

\begin{tabular}{llr}
\hline Age/ethnicity & Overweight/obesity & $\%$ \\
\hline 2-9 years & overweight & 8.1 \\
& obesity & 3.8 \\
\hline 9-18 years & overweight & 9.5 \\
& obesity & 2.3 \\
\hline 18-25 years & overweight & 20.8 \\
\hline Ethnic Dutch & obesity & 3.3 \\
\hline Western migrants & overweight & 11.4 \\
& obesity & 2.4 \\
\hline Nonwestern migrants & overweight & 10.3 \\
& obesity & 3.6 \\
\hline
\end{tabular}

\section{Overweight and Obesity in the Netherlands: Trends and Demographics}

\section{Time Trends in Childhood Obesity}

Data on the prevalence of childhood obesity before 1980 are not available. Before that, overweight and obesity were determined on the basis of percentiles of weight for height ( $>85$ th percentile for overweight; $>95$ th percentile for obesity). Since then three national growth studies were performed in children aged 2-20 years with current international ageand sex-specific body mass index cutoff points for trend analysis (Table 1) [1,2].

The national growth studies used measured height and weight. More recent studies were based on national surveys with height and weight reported by the parents. This probably leads to underestimation of overweight and obesity [3]. Comparison with earlier data should therefore be done with caution. In 2018 the combined prevalence of boys and girls aged 224 years was $15.8 \%$ (overweight, including obesity) and 3\% (obesity) [4].

As in many other countries overweight and obesity are more common in families with a relatively low socioeconomic status and in ethnic minorities (especially of Turkish and Moroccan descent), a specific high-risk group are children from families with Southeast Asian (Indonesian) and South Asian (India, Pakistan) background [5].

\section{Recent Comparisons with Other Countries}

According to the OECD [6] the prevalence of overweight (including obesity) in the Netherlands is relatively low. The OECD average (29 countries) for 15-year-olds was $15.5 \%$ in $2013 / 2014$, which was higher than that in the Netherlands $(12.5 \%)$. This figure compares favorably to many other countries and especially Greece (21.5\%), Canada (25.5\%), and the United States (31\%). The prevalence of overweight and obesity in the Netherlands differs by age and ethnicity (Table 2). The relatively high percentage of overweight and obesity in nonwestern migrants reflects the influence of social, cultural, and economic factors [7]. 
Seidell and Halberstadt: Childhood Obesity Prevention and Management in the Netherlands

Table 3. Social determinants of health (adapted and expanded from [12])

\begin{tabular}{|c|c|c|c|c|c|}
\hline $\begin{array}{l}\text { Economic } \\
\text { stability }\end{array}$ & $\begin{array}{l}\text { Neighborhood and } \\
\text { physical environment }\end{array}$ & Education & Food & $\begin{array}{l}\text { Community and } \\
\text { social context }\end{array}$ & Health care system \\
\hline $\begin{array}{l}\text { - Employment } \\
\text { - Income } \\
\text { - Expenses } \\
\text { - Debt } \\
\text { - Medical bills } \\
\text { - Support }\end{array}$ & $\begin{array}{l}\text { - Housing } \\
\text { - Transportation } \\
\text { - Safety } \\
\text { - Parks } \\
\text { - Playgrounds } \\
\text { - Walkability } \\
\text { - Zip code/geography }\end{array}$ & $\begin{array}{l}\text { - Literacy } \\
\text { - Language } \\
\text { - Early childhood } \\
\text { education } \\
\text { - Vocational training } \\
\text { - Higher education }\end{array}$ & $\begin{array}{l}\text { - Hunger and food insecurity } \\
\text { - Access to healthy food options } \\
\text { - Marketing of unhealthy convenient } \\
\text { highly processed foods } \\
\text { - Portion sizes } \\
\text { - Food pricing } \\
\text { - Food literacy }\end{array}$ & $\begin{array}{l}\text { - Social integration } \\
\text { - Support systems } \\
\text { - Community engagement } \\
\text { - Discrimination } \\
\text { - Stress }\end{array}$ & $\begin{array}{l}\text { - Health care coverage } \\
\text { - Provider availability } \\
\text { - Provider linguistic and } \\
\text { cultural competency } \\
\text { - Quality of care }\end{array}$ \\
\hline
\end{tabular}

\section{Determinants of Obesity in Children}

The remarkable increasing trends in childhood obesity over the past 50 years or so point to the importance of changing environmental factors, especially social determinants, that influence energy balance. This reflects changing local environments that are, in turn, driven by changes in the global food system [8]. Changes in environmental factors must be the main underlying determinants of increases in obesity because the genetic makeup of people has clearly remained unchanged over that period. The Netherlands is no exception with regard to the determinants of overweight in children as generally observed in high-income countries.

On an individual level the risk of obesity is only partly explained by hereditary factors. However, gene-environment interactions do largely explain why, in the same environment, some children become obese and others not. Genetic mutations with a strong effect on energy metabolism such as the ones in the leptin gene causing leptin deficiency are extremely rare. The more common variants and polymorphisms in genes only explain about $20 \%$ of the variance in body mass index [9]. Influences early in life such as epigenetics and the development of the gut microbiome can have lifelong consequences with respect to later risk of obesity and other noncommunicable diseases [10]. These influences as well as the importance of excessive weight gain in the first 2 years after birth are relevant in signaling high-risk individuals eligible for personalized prevention [11].

On a population level, however, the prevalence of obesity seems to be largely determined by social determinants of weight gain and health (Table 3). These factors, rather than individual ones, explain the large diversity of obesity in populations within and across countries, regions, towns, and neighborhoods. We expanded the table of Artiga and Hinton [12] with more aspects of the food environment that are related to obesogenic environments $[13,14]$. In addition, it has been shown that cultural determinants may have an impact on the prevalence of obesity [15].

The food environment is an important driver of food choice and intake [16]. Clues from associations between the food environment and obesity in children point to targets for intervention such as presence of food promotion and availability of large portion sizes and sugarsweetened soft drinks. Similarly, the social determinants in Table 3 influence sedentary behavior and physical activity as well as sleep duration and quality. Diet, activity, and sleep are directly related to weight and their social determinants are therefore considered to be of major importance as targets for intervention [17].

Many aspects of the social determinants of health are interrelated and usually not in a linear fashion with the behaviors they affect. One way to assess the causal web of factors in specific situations (e.g., systems such as neighborhoods, towns, or regions) is to draw up causal loop diagrams [18]. Such causal loop diagrams can be based on factors identified from the literature and complemented and elaborated by perspectives from the community. This can provide the basis for community-led planning for an integrated approach to tackle obesity.

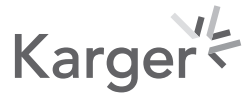


Seidell and Halberstadt: Childhood Obesity Prevention and Management in the Netherlands

\section{WHO-Recommended Strategies for Prevention}

In all likelihood the most authoritative set of recommendations for governments and other stakeholders is from the WHO's Report of the Commission on Ending Childhood Obesity from 2016 [19]. The recommendations call for all countries to remedy the obesogenic environments, take a life course approach in promoting obesity prevention, and improve the treatment of children who already have obesity. The commission identified six key areas of action: (1) Promote the intake of healthy foods; e.g., adequate nutrition information (labeling); implementation of a sugar-sweetened beverage tax; restriction of marketing of unhealthy foods and drinks to children; requirements for healthy food environments in settings such as schools and sports facilities; increase availability of healthy foods in disadvantaged communities. (2) Promote physical activity; e.g., guidelines for physical activity, sedentary behavior, and screen time; availability of facilities in schools and public spaces. (3) Preconception and pregnancy care; e.g., monitoring of gestational weight gain and glucose and blood pressure during pregnancy; lifestyle guidance before conception and during pregnancy. (4) Early childhood diet and physical activity; e.g., ensure adequate breastfeeding and regulation of marketing complementary foods and drinks; limit sugar-sweetened beverages and energy-dense nutrientpoor foods; healthy food and physical activity practices in day care; guidance on appropriate sleep time, sedentary or screen time, and physical activity and play; whole-of-community approaches to promote healthy lifestyles. (5) Health, nutrition, and physical activity for schoolaged children; e.g., healthy food environment in schools and elimination of sugar-sweetened drinks and energy-dese nutrient-poor foods; access to clean tap water; nutrition and health education including food preparation classes; quality physical activity. (6) Weight management; e.g., develop and support appropriate weight management services for children and adolescents who have overweight or obesity that are family-based and multicomponent delivered by trained health professionals; make these services part of universal health coverage.

\section{Local Strategies for Prevention}

Ideally an integrated-systems approach should be considered in order to tackle up- and downstream determinants in a sustainable fashion and taking a life-course approach starting with the first 1,000 days after conception. In such an approach there is need for applying single-setting interventions that have been evaluated in terms of effectiveness. A recent overview by Bleich et al. [20] identified school-based interventions with combined diet and physical activity components and a home element as being the most effective. There was limited evidence to support interventions that are preschool-based, community-based, or home-based. This does not mean that integrating such interventions in an integrated approach is not meaningful, but just that they have been inadequately studied.

Although school-based interventions such single-setting interventions are promising, they are no guarantee for successful obesity prevention on a population level [21]. Efforts to focus more on upstream determinants and use of whole-systems approaches are therefore recommended. With a whole-systems approach we mean engaging the whole system as well as using system approaches and thinking. The UK's National Institute for Health and Care Excellence (NICE) has provided recommendations for the development of sustainable, community-wide approaches to obesity [22]. This includes recommendations on (1) strategic leadership and coordinating local action, (2) involving the community, local businesses, and social enterprises, (3) local authorities and the National Health Service as exemplars of good practice, (4) planning and implementing systems for monitoring and evaluation, and (5) scrutiny and accountability.

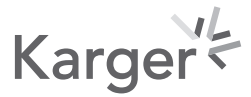


Seidell and Halberstadt: Childhood Obesity Prevention and Management in the Netherlands

The methodologies for operationalization and evaluation of whole-systems approaches are still in development. Bagnall et al. [23] recently extensively reviewed the current knowledge about whole-systems approaches to obesity. This review concluded that there is a need for an agreed definition of a whole-systems approach in relation to obesity. Furthermore, there should be a consistency of language and definition across sectors. Finally, detailed descriptions of what was actually done are necessary for full appreciation and, finally, they should include process and economic evaluations.

\section{National Policy for Childhood Obesity in the Netherlands: The Prevention Agreement (2018)}

In the Netherlands, the problem of increasing obesity in children was acknowledged widely by health care professionals. In 2004, Renders et al. [24] reported that no known preventative intervention or policies were in place. In 2009, the Dutch Ministry of Health, Welfare, and Sports published the first national report on obesity. The report emphasized many activities on health promotion and the role of individual responsibility. It also highlighted two programs including improved health care for children who already had overweight or obesity ("Partnership Overweight Netherlands") and the implementation of a local approach ("Young People at a Healthy Weight" [JOGG]) based on the French "Ensemble Prévenons l'Obésité des Enfants" (EPODE) program [25]. No national regulatory policies on marketing, pricing, or food composition were included. This approach relied heavily on the involvement of the system of Municipal Health Services in the Netherlands, which is responsible for youth health care and collective prevention.

Between 2009 and 2018, it was concluded by the ministry that insufficient progress was being made. The national government decided therefore to emphasize policies on prevention around smoking, harmful use of alcohol, and overweight [26]. For overweight they installed a committee in which agreements were brokered with 70 organizations that represented a wide variety of stakeholders including associations of health charities, municipalities, primary and secondary education, municipal health services, health professionals, and health care insurance companies. More controversial was that also associations of the food industry, supermarkets, catering companies, and restaurants were part of the deliberations.

The agreed ambition was, among others, to reduce the prevalence of childhood overweight (including obesity) from $13.5 \%$ in 2018 to $9.1 \%$ in 2040 and childhood obesity from 2.8 to $2.3 \%$. This meant to reduce the prevalence of overweight and obesity in children in the next 22 years to those 22 years before 2018. Some of the agreed measures in the national prevention agreement were the following: (1) In 2020, a minimum of 2,500 sports clubs will provide members and visitors with healthier foods and drinks (complying with the most recent national dietary guidelines from 2015). (2) In 2020, at least 950 school canteens will offer healthier foods and drinks to staff and students. (3) In 2025, at least half of the hospitals will provide healthier foods to patients, personnel, and visitors. (4) Food manufacturers will reformulate products by adding less sugar and reducing portion size. (5) Starting in 2019, the national government and supermarkets will intensify spreading knowledge related to dietary recommendations. (6) In 2020, the government will introduce a new front-of-pack logo for foods and drinks that will aid consumers to make healthier choices. (7) Integrated care with tailored support for healthier lifestyles will be available for children with overweight or obesity in 35 municipalities in 2020 and in all municipalities in 2030. (8) Sports clubs will make their services more available and accessible for those with insufficient physical activity. (9) Drinking water will be made more readily available, e.g., trough water taps in public places and schools. (10) The use of licensed media 
Seidell and Halberstadt: Childhood Obesity Prevention and Management in the Netherlands

characters aimed at children under 13 years will be reduced on packaging of foods and on point of sales material.

The agreement was published in November 2018 and met with different reactions. Some considered the measures to reflect that the government wanted to move to a "nanny state," taking away the individual responsibility of citizens. Others were concerned that these measures would be insufficiently effective to reach the targets for reducing overweight and obesity. The National Institute of Public Health calculated the potential impact of the measures. Many of the measures were vague and unspecific, and therefore it was unclear what their impact would be in the long run. For those that allowed impact analysis, it was clear that the achieved reductions would have a minimal impact on the projected future increase in the prevalence of overweight and obesity and therefore would not lead to achieving the agreed targets. The Ministry of Health announced that further monitoring and deliberations would follow to increase the impact of the agreement.

In comparison with the recommendations of the WHO's Report of the Commission on Ending Childhood Obesity [19], it is clear that the national strategy in the Netherlands strongly relies on self-regulation by the different stakeholders and is weak on regulatory policies regarding the food environment.

\section{Local Integrated Approaches in the Netherlands}

Since 2010 the national government and municipalities are supporting the JOGG program. JOGG is a programmatic local approach that was originally modeled on the French EPODE program; together we prevent obesity in children [25]. EPODE is a large-scale, centrally coordinated, capacity-building approach for local communities to implement effective and sustainable strategies to prevent obesity [27].

The JOGG approach is based on five pillars: (1) political and governmental support (including domains that are generally outside public health such as town planning, education, transportation, and social domains); (2) cooperation between the private and the public sector (preferably involving local stores and supermarkets as well as small to medium enterprises related to food supply); (3) social marketing (the use of marketing principles to promote healthier behavior); (4) scientific evaluation and dissemination (taking a "learning approach" towards program evaluation, including evaluation of effectiveness of interventions and process evaluations); and (5) linking prevention and health care (preventing that children will need obesity management and, when they do, make sure they will live in situations that support behavior change that results from management programs).

Municipal activities are coordinated at the national level by the JOGG foundation. Each municipality has its own JOGG coordinator who plans the activities with the different local stakeholders. These activities are tailored to local needs and opportunities. Most of the activities are geared towards changes in the environment (homes, schools, health care, and neighborhoods), but also involve strategies targeting individuals (improving attitudes, awareness, skills, and knowledge). There is particular attention towards the reduction of social inequalities in health. In May 2020 there were 144 municipalities that implemented the JOGG approach reaching well over one million children. In 29 of these the prevalence of overweight in children was decreasing [28]. Increasingly, this local integrated approach is using a whole-systems approach.

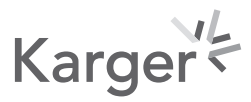


Seidell and Halberstadt: Childhood Obesity Prevention and Management in the Netherlands

\section{History and Present of Public Health in Amsterdam}

Amsterdam has a long history of integrated policies and practices regarding public health. Perhaps the strongest example of this was led by the 19th-century physician Samuel Sarphati (1813-1866). He realized that the health inequalities observed in the city about 200 years ago were largely the result of poor environmental conditions. Sarphati became involved in politics, particularly as a project developer in city planning. Besides public health, he initiated improvements in education and industrialization. To make bread affordable to the poor he created the first Dutch bread factory, and he played an important role in a refuse collection service and a waste transport system in 1847 . This would currently probably be considered a whole-systems approach to combat diseases such a cholera and malnutrition.

In 1893 the first municipal health service in the Netherlands was created in Amsterdam to combat "hygiene-related" diseases. In 1901 this was expanded to a broad public healthoriented service for all citizens, with notable emphasis on the care for newborns and for those who were poor.

The municipal health service now also adopts a whole-systems approach towards obesity: the Amsterdam Healthy Weight Programme (AAGG) [10, 29]. In 2012, an Amsterdam city council's alderman and deputy mayor brought the municipality's political leaders together to commit to doing something bold and mission-led. In 2013, the AAGG was launched with the aim of supporting children and parents to be healthier by engaging with them. This was accompanied by strategies that involved professionals and organizations that work with children or significantly influence their lifestyles. In contrast to an only treatment-based approach or an only prevention-based approach, the AAGG focuses on prevention and treatment with integrated, cross-sector, and cross-departmental actions involving politicians, local authorities, schools, medical professionals, planning bodies, sports organizations, communities and neighborhoods, charities, and the business sector. Initially the program did not have any additional budget, but since 2015 annual funding of EUR 2.5 million has been assigned to the program, with about a further EUR 2.73 million committed from the national government and allocated by the Amsterdam municipal authorities to specific projects within the overall program. However, funding is not the most important driver of success, with strategic, integrated working to a common cause being the principle enabler [30]. Critical elements of this approach have been identified and are shown in Table 4 [31].

In the program, preventive interventions take place during the first 1,000 days (from conception to 2 years old) in schools (from preschool to secondary), in neighborhoods (including targeting efforts and monitoring success), and in the creation of a healthy environment (including urban design and regulation of the food and drinks industry, such as restricting unhealthy marketing to children). Curative interventions are also part of the program and target children who already have overweight or obesity, with the aim of helping them to regain a healthier weight [32].

Originally the Amsterdam approach was developed based on the Dahlgren and Whitehead "rainbow model" for tackling social inequalities in health [33]. In retrospect, compared to the recommendations of the NICE for working with local communities, it seems that the approach in Amsterdam has covered all recommendations in some way. With regard to the gaps in the knowledge about the effectiveness of whole-systems approaches, as identified by Bagnall et al. [23], the Amsterdam approach may, over time, contribute to partially filling them. The Amsterdam approach is currently still developing its operationalization and evaluation. In order to be pragmatic, Amsterdam has taken a "learning approach." This means that activities and policies are carefully monitored in terms of processes and effects and are continuously adapted in response to experiences. Recently, relatively new concepts such as system map building and group model building have been applied for the development of new interven-

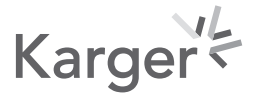


Table 4. The yardstick with valuable elements for an integrated approach towards excessive weight among children [31]

Active elements

1. Programmatic approach

- Theoretical underpinning of program (components)

- Systematic approach

- Participation of the (final) target group in planning and implementation

- Clearly specify several target groups

- Working according to standards and guidelines of the programmatic approach

- Community-wide and cross-sectoral

2. Leadership

- Political-administrative basis

- The integrated approach is an explicit priority of policy

- Coordination of program components and the whole

- Central and local leadership (administrative, official, and executive)

- Commitment to transformational leadership including change strategy

- Deployment of employees with the right skills, expertise, and knowledge

- Stimulating the commitment of employees, aimed at intrinsic motivation

3. Intervention development and implementation

Preference for proven effective interventions, but:

- Interventions must fit in with the context (area-based work)

- Interventions are aimed at reducing social inequalities

- Interventions are consistent with national and regional policies

- Interventions are in line with existing methods and strategies

- The use of a mix of different strategies at different levels and settings and focused on nutrition, exercise, and sleep (preferably scientifically based)

4. Integral cooperation

Integral and transparent cooperation with public and private local stakeholders, with:

- Common goal/interest: insight into the added value of cooperation

- Clear cooperation agreements on roles and responsibilities

- Direction and coordination arranged at different levels

- Investment in common language, work processes, and working conditions

5. The learning approach

- Use of knowledge (scientific, practical, and experience)

- Monitoring determinants and health outcomes

- Systematic reflection on outcomes (critical reflection)

- Structured evaluation plan

- Evaluation and monitoring of processes and impacts

- Adapting interventions on the basis of evaluation and identified changes in the system; use of actions for improvement

- Evaluation aimed at recognizing the contribution of an integrated approach to long-term objectives

6. Long-term vision aimed at lasting change

- Multi-annual plan with a mission of $>20$ years

- Solid administrative and policy base

- Those involved are encouraged to take ownership

- Continuing changes in the environment support the desired behavior

- Focus on health in all policies

- Budget earmarked for the integrated approach

- Sufficient staff capacity

- Securing in good time 
Seidell and Halberstadt: Childhood Obesity Prevention and Management in the Netherlands

Table 4 (continued)

Active elements

7. Communication and marketing

- Setting a standard

- Obtaining a sense of urgency

- Sending an unambiguous positive message and increasing its reach

- Limiting marketing of unhealthy foods and beverages aimed at children

- Deployment of behavioral insights to connect means of communication to the perception of target groups

- Use of the socioecological model designed specifically for the prevention of overweight and obesity in children

tions and for the evaluation of the approach. It is one of the characteristics of a systems approach that it is dynamic, nonlinear, and adapted over time. This obviously makes it more difficult to demonstrate its effectiveness as would be possible with a randomized clinical trial with a fixed intervention and a control group. The ten features of a systems approach as mentioned by Bagnall et al. [23]) are all present in the Amsterdam approach (Table 4), but to which degree is difficult to quantify.

\section{Integration of Prevention and Management of Obesity in Children}

As is broadly acknowledged, part of an integrated approach to tackle obesity is the availability of appropriate obesity treatment for those who need it [19]. International consensus and guidelines for obesity treatment outline that the core of these treatments should be multicomponent (including nutrition, physical activity, and psychosocial support), familybased, and that the treatment should be part of universal health care coverage [19, 34].

The implementation of such guidelines can prove to be a challenge. In the Netherlands the first successful steps towards implementation for children have been taken in the past few years. This started with the development of a national multidisciplinary health care standard for obesity based on the national guideline [34, 35]. The next step was the development of a national model for integrated care for childhood overweight and obesity, based on the standard and the guideline [36]. This model consists of four parts: (1) vision (how to achieve a broad assessment of the child and his/her environment), (2) process (the six steps of the trajectory: diagnosis, broad assessment, discussion of approach, making plan and dividing tasks, get to work, sustaining the changes), (3) partners (who is involved from the health care domain and social care domain in the different steps), and (4) financing (how to achieve local funding of all parts of the integrated care).

The national model for integrated care for childhood overweight and obesity was developed in a pilot by the Vrije Universiteit Amsterdam with eight Dutch municipalities, thus combining knowledge from science, policy, and practice. The Dutch Ministry of Health, Welfare, and Sports that co-financed this pilot decided to finance the next phase of further development and implementing this model in 35 municipalities by 2020 as well as evaluation of the local implementation. This implementation phase will be executed in close collaboration with JOGG. The result of this collaboration is integrated care in an environment of integrated prevention, which makes both stronger and results in an integrated-systems approach. The aim of the Dutch Ministry of Health, Welfare, and Sports is to have integrated care for children with overweight and obesity implemented in all municipalities in the Netherlands by 2030 [26]. 
Seidell and Halberstadt: Childhood Obesity Prevention and Management in the Netherlands

\section{Conclusion}

The global rise in childhood obesity can be considered a pandemic. This reflects structural and increasing imbalances in energy balance which are largely driven by upstream societal changes. A successful strategy aimed at reducing the prevalence of obesity in children needs to acknowledge these underlying social determinants of behavior and needs to take a life course approach starting at conception.

The current national and local approaches towards the prevention of obesity in children have the advantage of having very specific targets in the long run (2040), have taken a theorybased integrated whole-systems approach with participatory action, and include settingbased evidence-based health promotion interventions. The national policies rely heavily on self-regulation by stakeholders such as supermarkets, restaurants, and the food industry. They lack for the most part regulatory policies targeting the food environment in public spaces (schools, hospitals, sports facilities) and marketing of unhealthy foods and drinks to children as proposed by the WHO [37]. Local policies and actions such as the whole-systems approach in Amsterdam are promising. Future directions include the development of tools for the operationalization and evaluation of local systems approaches.

\section{Acknowledgement}

This paper is an extended and updated version of the text of a lecture delivered at the NUTRIMAD conference ("Public Health Nutrition in the 21st Century") in Madrid, Spain, October 24-27, 2018. The authors express gratitude to their numerous colleagues for their contributions to the prevention and management of obesity in children.

\section{Conflict of Interest Statement}

The authors have no conflicts of interest to declare.

\section{Funding Sources}

The authors are funded by the Vrije Universiteit Amsterdam as well as the Dutch Ministry of Health, Welfare, and Sports and the municipality of Amsterdam. There was no special funding for the writing of this paper.

\section{Author Contributions}

Both authors were involved in the writing of the manuscript. 


\begin{tabular}{|c|c|}
\hline \multicolumn{2}{|l|}{ Obes Facts $2020 ; 13: 418-429$} \\
\hline DOI: $10.1159 / 000509588$ & $\begin{array}{l}\text { (c) } 2020 \text { The Author(s). Published by S. Karger AG, Basel } \\
\text { www.karger.com/ofa }\end{array}$ \\
\hline
\end{tabular}

\section{References}

1 Schönbeck Y, Talma H, van Dommelen P, Bakker B, Buitendijk SE, Hirasing RA, et al. Increase in prevalence of overweight in Dutch children and adolescents: a comparison of nationwide growth studies in 1980, 1997 and 2009. PLoS One. 2011;6(11):e27608.

2 Cole TJ, Bellizzi MC, Flegal KM, Dietz WH. Establishing a standard definition for child overweight and obesity worldwide: international survey. BMJ. 2000 May;320(7244):1240-3.

3 Jansen W, van de Looij-Jansen PM, Ferreira I, de Wilde EJ, Brug J. Differences in measured and self-reported height and weight in Dutch adolescents. Ann Nutr Metab. 2006;50(4):339-46.

4 Statistics Netherlands. Press release: One quarter of young adults are overweight. 2019. Available from: https://www.cbs.nl/en-gb/news/2019/15/one-quarter-of-young-adults-are-overweight (accessed May 15, 2020).

5 de Wilde JA, van Dommelen P, Middelkoop BJ, Verkerk PH. Trends in overweight and obesity prevalence in Dutch, Turkish, Moroccan and Surinamese South Asian children in the Netherlands. Arch Dis Child. 2009 Oct; 94(10):795-800.

6 OECD. Obesity Update 2017. Available from: www.oecd.org/els/health-systems/Obesity-Update-2017.pdf (accessed May 15, 2020).

7 de Wilde JA, Eilander M, Middelkoop BJ. Effect of neighbourhood socioeconomic status on overweight and obesity in children 2-15 years of different ethnic groups. Eur J Public Health. 2019 Aug;29(4):796-801.

8 Swinburn BA, Sacks G, Hall KD, McPherson K, Finegood DT, Moodie ML, et al. The global obesity pandemic: shaped by global drivers and local environments. Lancet. 2011 Aug; 378(9793):804-14.

9 Chesi A, Grant SF. The genetics of pediatric obesity. Trends Endocrinol Metab. 2015 Dec;26(12):711-21.

10 Seidell JC, Halberstadt J. Lifelong impact of nutrition in the first thousand days after conception. Early Child Matters. 2018;127:94-9.

11 Ong KK, Loos RJ. Rapid infancy weight gain and subsequent obesity: systematic reviews and hopeful suggestions. Acta Paediatr. 2006 Aug; 95(8):904-8.

12 Artiga S, Hinton E. Beyond health care: the role of social determinants in promoting health and health equity. 2018. Available from: www.kff.org/disparities-policy/issue-brief/beyond-health-care-the-role-of-socialdeterminants (accessed May 15, 2020).

13 Mattes R, Foster GD. Food environment and obesity. Obesity (Silver Spring). 2014 Dec;22(12):2459-61.

14 Hall KD. Did the food environment cause the obesity epidemic? Obesity (Silver Spring). 2018 Jan;26(1):11-3.

15 Wallace C, Vandevijvere S, Lee A, Jaacks LM, Schachner M, Swinburn B. Dimensions of national culture associated with different trajectories of male and female mean body mass index in countries over 25 years. Obes Rev. 2019 Nov;20(Suppl 2):20-9.

16 Osei-Assibey G, Dick S, Macdiarmid J, Semple S, Reilly JJ, Ellaway A, et al. The influence of the food environment on overweight and obesity in young children: a systematic review. BMJ Open. 2012 Dec;2(6):e001538.

17 Dollet L, Zierath JR. Interplay between diet, exercise and the molecular circadian clock in orchestrating metabolic adaptations of adipose tissue. J Physiol. 2019 Mar;597(6):1439-50.

18 Allender S, Owen B, Kuhlberg J, Lowe J, Nagorcka-Smith P, Whelan J, et al. A community based systems diagram of obesity causes. PLoS One. 2015 Jul;10(7):e0129683.

19 Commission on Ending Childhood Obesity. Report of the Commission on Ending Childhood Obesity. Geneva: World Health Organization; 2016.

20 Bleich SN, Vercammen KA, Zatz LY, Frelier JM, Ebbeling CB, Peeters A. Interventions to prevent global childhood overweight and obesity: a systematic review. Lancet Diabetes Endocrinol. 2018 Apr;6(4):332-46.

21 Lloyd J, Creanor S, Logan S, Green C, Dean SG, Hillsdon M, et al. Effectiveness of the Healthy Lifestyles Programme (HeLP) to prevent obesity in UK primary-school children: a cluster randomised controlled trial. Lancet Child Adolesc Health. 2018 Jan;2(1):35-45.

22 National Institute for Health and Care Excellence (NICE). Obesity: working with local communities. Public Health Guideline 42, 2012. Available from: https://www.nice.org.uk/guidance/ph42 (accessed May 15, 2020).

23 Bagnall AM, Radley D, Jones R, Gately P, Nobles J, Van Dijk M, et al. Whole systems approaches to obesity and other complex public health challenges: a systematic review. BMC Public Health. 2019 Jan;19(1):8.

24 Renders CM, Seidell JC, van Mechelen W, Hirasing RA. Overgewicht en obesitas bij kinderen en adolescenten en preventieve maatregelen. Ned Tijdschr Geneeskd. 2004 Oct;148(42):2066-70.

25 Borys JM, Le Bodo Y, Jebb SA, Seidell JC, Summerbell C, Richard D, et al.; EEN Study Group. EPODE approach for childhood obesity prevention: methods, progress and international development. Obes Rev. 2012 Apr; 13(4):299-315.

26 Ministry of Health, Welfare, and Sports. Nationaal Preventieakkoord [National Prevention Agreement], 2018. Available from: https://www.rijksoverheid.nl/documenten/convenanten/2018/11/23/nationaal-preventieakkoord (accessed May 15, 2020).

27 Van Koperen TM, Jebb SA, Summerbell CD, Visscher TL, Romon M, Borys JM, et al. Characterizing the EPODE logic model: unravelling the past and informing the future. Obes Rev. 2013 Feb;14(2):162-70.

28 Young People at a Healthy Weight (JOGG). Available from: www.jongerenopgezondgewicht.nl (accessed May $15,2020)$. 
29 Amsterdam Healthy Weight Programme. Available from: https://www.amsterdam.nl/bestuur-organisatie/ organisatie/sociaal/onderwijs-jeugd-zorg/blijven-wij-gezond/amsterdam-healthy (accessed May 15, 2020).

30 European Commission. Health Equity Pilot Project (HEPP). Amsterdam Healthy Weight Programme. Case Study. 2018. Available from: https://ec.europa.eu/health/sites/health/files/social_determinants/docs/ hepp_case-studies_07_en.pdf (accessed May 15, 2020).

31 Koperen MT, van Wietmarschen M, Seidell J, Hageraats R. Amsterdamse Aanpak Gezond Gewicht (Amsterdam Healthy Weight Approach): likely to succeed? A search for the valuable elements; report 2018. Available from: https://www.amsterdam.nl/sociaaldomein/blijven-wij-gezond/amsterdam-healthy (accessed May $15,2020)$.

32 Hawkes C, Russell S, Isaacs A, Rutter H, Viner R. What can be learned from the Amsterdam Healthy Weight programme to inform the policy response to obesity in England? Obesity Policy Research Unit (OPRU): Rapid response briefing paper. 2017. Available from: https://www.ucl.ac.uk/obesity-policy-research-unit/sites/ obesity-policy-research-unit/files/what-learned-from-amsterdam-healthy-weight-programme-informpolicy-response-obesity-england.pdf (accessed May 15, 2020).

33 Dahlgren G, Whitehead M. European strategies for tackling social inequities in health: levelling up Part 2. WHO Regional Office for Europe 2006. Available from: http://www.euro.who.int/_data/assets/pdf_ file/0018/103824/E89384.pdf (accessed May 15, 2020).

34 Seídell JC, de Beer JJ, Kuijpers T. Richtlijn "Diagnostiek en behandeling van obesitas bij volwassenen en kinderen" [Guideline "Diagnosis and treatment of obesity in adults and children"]. Ned Tijdschr Geneeskd. 2008 Sep;152(38):2071-6.

35 Seidell JC, Halberstadt J, Noordam H, Niemer S. An integrated health care standard for the management and prevention of obesity in The Netherlands. Fam Pract. 2012 Apr;29(Suppl 1):i153-6.

36 Sijben M, van der Velde M, van Mil E, Stroo J, Halberstadt J. Landelijk model ketenaanpak voor kinderen met overgewicht en obesitas [National model integrated care for children with overweight and obesity]. Amsterdam: Care for Obesity, 2018. Available from: https://beta.vu.nl/nl/Images/Landelijk_model_digitaal_ tcm235-928414.pdf (accessed May 15, 2020).

37 Panter J, Tanggaard Andersen P, Aro AR, Samara A. Obesity Prevention: A Systematic Review of Setting-Based Interventions from Nordic Countries and the Netherlands. J Obes. 2018 Apr;2018:7093260. 